\title{
GP5 protein-based ELISA for the detection of PRRSV antibodies
}

\author{
Y. Wang ${ }^{1,2}$, J. Guo², S. Qiao ${ }^{2}$, Q. Li $^{2}$, J. Yang ${ }^{2}$, \\ Q. Jin' ${ }^{2}$ G. Zhang \\ ${ }^{1}$ School of Public Health, Xinxiang Medical University, Xinxiang, 453003, P.R. China \\ ${ }^{2}$ Key Laboratory of Animal Immunology of the Ministry of Agriculture, \\ Henan Key Laboratory of Animal Immunology, Henan Academy of Agricultural Sciences, \\ Zhengzhou 450002, P.R. China \\ ${ }^{3}$ College of Veterinary Medicine and Animal Science, Henan Agricultural University, \\ Zhengzhou 450002, P.R. China
}

\begin{abstract}
Porcine reproductive and respiratory syndrome virus (PRRSV) is an important swine pathogen, causing huge economic losses each year worldwide. Immunization with vaccines containing the glycoprotein 5 (GP5) of PRRSV is the main measure to induce neutralizing antibodies and control the disease. Here, we developed a GP5 protein-based ELISA for detecting antibodies against PRRSV. The overall yield of purified GP5 in E. coli flask culture was more than $45 \mathrm{mg} / \mathrm{L}$ cell culture. Western blot and IFA indicated that the GP5 protein was highly immunogenic. After optimization and validation with IDEXX PRRS using 566 clinical sera, the DSN, DSP, and accuracy of GP5-ELISA were $81.39 \%, 75.96 \%$, and $80.39 \%$, respectively. Besides, GP5-ELISA is highly specific, showing no cross-reactions with sera against other important swine pathogens. Hence, GP5 is a good diagnostic antigen and the GP5 protein-based ELISA has the potential to be used in the field.
\end{abstract}

Key words: PRRSV, GP5 protein, ELISA, antibody detection

\section{Introduction}

Porcine reproductive and respiratory syndrome (PRRS) was first reported in America in 1987, and has become one of the most economically important swine diseases worldwide (Keffaber 1989, Collins et al. 1992). The disease is characterized by severe reproductive failure in sows and a high rate of respiratory diseases and mortality in young pigs (Kimman et al. 2009). Its causative agent, PRRSV, was first isolated in the Netherlands in 1991 (Lelystad virus, LV) and one year later in North America (ATCC-VR-2332) (Wensvoort et al. 1991, Collins et al. 1992). In China, a PRRS outbreak occurred at the end of 1995 and the disease has been one of the most significant problems for swine production, resulting in great economic losses each year (Gao et al. 2004). At present, most identified PRRSV Chinese isolates belong to the NA-type (Ren et al. 2010). 
PRRSV belongs to the family Arteriviridae, consisting of lactate dehydrogenase-elevating virus (LDV), equine arteritis virus (EAV) and simian hemorrhagic fever virus (SHFV) (Meulenberg et al. 1993). The primary structural proteins of PRRSV are the nucleocapsid $(\mathrm{N})$ protein, the membrane/matrix $(\mathrm{M})$ protein and the primary envelope glycoprotein GP5 (Plagemann et al. 2006). Early antibodies mounted by PRRSV infection are mainly directed to the N-protein and, to a lesser extent, to the M-protein and are non-neutralizing (Nelson et al. 1994, Gonin et al. 1999, Dea et al. 2000). Neutralizing antibodies are mainly directed against GP5, and the primary neutralization epitope of PRRSV strain VR-2332 is located in the middle of the GP5 ectodomain (amino acids 36-52) (Pirzadeh and Dea 1997, Gonin, et al. 1999, Plagemann et al. 2002, Ferrin et al. 2004). Hence, the development of an ELISA based on GP5 protein is essential for evaluating PRRSV vaccine efficacy and indicating the presence of neutralizing antibodies in vivo.

Serological testing to determine viral infection status of swine herds and individual animals is often included in management strategies for disease surveillance and control (Ferrin et al. 2004, Pejsak et al. 2014, Wernicki et al. 2015). Various serological tests have been developed for the detection of PRRSV-specific antibodies in swine sera. The immunoperoxidase monolayer assay (IPMA) (Wensvoort et al. 1991) and the indirect immunofluorescence assay (IFA) (Yoon et al. 1992) are based on the specific binding of antibodies to viral antigens cultivated in porcine alveolar macrophages or MARC-145 cells. Yet both tests are laborious and not suitable for routine testing on a large scale with the disadvantages of the need of a replicating virus (Dea et al. 2000). Indirect or competitive enzyme-linked immunosorbent assays (ELISAs) have been reported by several groups of investigators (Albina et al. 1993, Cho et al. 1996, Dea et al. 2000, Nowicka et al. 2014). These ELISA procedures are simple, quick, sensitive, and specific. Besides, ELISA has the advantage for high-throughput testing of serum samples, which facilitates its use in the field. The IDEXX HerdChek PRRS ELISA is primarily used and considered as the gold standard for the diagnosis of PRRSV infection of pigs in the swine industry (Plagemann et al. 2006, Foti et al. 2008).

In this paper, we constructed a prokaryotic expression plasmid pET28a-GP5 containing the extraand intra-cellular sequences of GP5 protein fused together with a linker sequence for GGGGS. Over-expression of the GP5 protein was achieved in E. coli. After evaluation of the immunogenicity of the protein, a GP5-based ELISA for the detection of PRRSV antibodies was established and validated with IDEXX HerdChek 2XR ELISA.

\section{Materials and Methods}

\section{Plasmids and bacterial strains}

The prokaryotic plasmid pET28a-GP5 contains the ectodomain sequence of GP5 (32-63 aa), a linker sequence for GGGGS, and the endodomain sequence of GP5 protein (130-200 aa). The construct was ligated together with splice overlap-extension PCR as described in (Wang et al. 2011). E. coli strain Rosetta (DE3) competent cells were purchased from Novagen, USA.

\section{Virus and sera}

MARC-145 cell line was maintained in Dulbecco's modified Eagle's medium (DMEM, Sigma) supplemented with $10 \%$ fetal bovine serum (FBS, Invitrogen). PRRSV strain HN07-1 was isolated in Henan province of China in 2007 and propagated in MARC-145 cells. PRRSV negative and positive sera were obtained from the SPF and HN07-1 immunized pigs, respectively. Positive sera for Porcine circovirus type 2 (PCV2), Classical swine fever virus (CSFV), Japanese encephalitis virus (JEV), Pseudorabies virus (PRV) and Porcine parvovirus (PPV) were purchased from the Chinese Institute of Veterinary Drug Control. A total of 566 clinical swine sera were collected in different regions of Henan, China.

\section{Antigen preparation}

Recombinant E. coli Rosetta (DE3) cells bearing GP5 gene were cultured in LB liquid medium and induced by a final concentration of $1.0 \mathrm{mM}$ isopropyl- $\beta$-D-thiogalactoside (IPTG) for $6 \mathrm{~h}$ at $37^{\circ} \mathrm{C}$. Then, the cells were pelleted and resuspended in phosphate buffered saline (PBS), and then lysed by ultra-sonication on ice. After centrifugation at 6,000 $\mathrm{g}$ for $20 \mathrm{~min}$ at $4^{\circ} \mathrm{C}$, the pellets were collected and solubilized in $50 \mathrm{mM}$ Tris- $\mathrm{HCl}(\mathrm{pH} 8.0)$ containing $8 \mathrm{M}$ urea, $0.5 \mathrm{M} \mathrm{NaCl}, 5 \mathrm{mM}$ 2-mercaptoethanol $(\beta-\mathrm{ME})$ and $5 \mathrm{mM}$ imidazole overnight at $4^{\circ} \mathrm{C}$. Following centrifugation at $12,000 \mathrm{~g}$ for $15 \mathrm{~min}$, the supernatant was filtered through a $0.22 \mu \mathrm{m}$ filter (Millipore, Billerica, MA, USA) to remove remaining particles and loaded onto Ni-chelate affinity column for purification and then refolded by gradual dialysis against decreasing concentrations of urea (8 
$\mathrm{M}-6 \mathrm{M}-4 \mathrm{M}-2 \mathrm{M}-1 \mathrm{M}-0.5 \mathrm{M}-0 \mathrm{M})$. The purity and immunogenicity of GP5 protein was examined by SDS-PAGE and Western blot, respectively. The refolding yield was calculated as a percentage of the content of soluble protein after refolding against the content of total protein of inclusion bodies before refolding. Purified GP5 protein was stored at $-80^{\circ} \mathrm{C}$ and the concentration was determined with a BCA Protein Assay Kit.

\section{Indirect immunofluorescence assay (IFA)}

Monolayers of MARC-145 cells grown in 96-well plates were incubated with PRRSV at $37^{\circ} \mathrm{C}$ in $5 \%$ $\mathrm{CO}_{2}$ atmosphere for $48 \mathrm{~h}$, xed in cold methanol for 15 minutes, blocked with $5 \%$ skimmed milk, and stored at $-20^{\circ} \mathrm{C}$ until used. Positive swine sera against PRRSV and mouse polyclonal antibodies were respectively employed as primary antibodies for incubation with the prepared plates. Upon washing 3 times with PBST, $50 \mu$ l of rabbit anti-swine IgG-FITC and goat anti-mouse IgG-FITC were added to the corresponding wells as secondary antibodies. After 3 washings, the plates were examined under a fluorescence microscope. Mock-infected MARC-145 cells were used as negative controls.

\section{ELISA procedure}

96-well microtiter plates manufactured from polyvinyl chloride were coated with $50 \mu \mathrm{l} \mathrm{GP5}$ protein in carbonate buffered saline (CBS, $\mathrm{pH} 9.6)$ and incubated overnight at $4^{\circ} \mathrm{C}$. After three washes in PBS containing $0.05 \%$ Tween 20 (PBST), the plates were incubated with blocking buffer $(5 \%$ skimmed milk) for $1 \mathrm{~h}$ at $37^{\circ} \mathrm{C}$ and with $50 \mu$ l serum samples diluted in PBS containing $5 \%$ E. coli lysate for 30 min at $37^{\circ} \mathrm{C}$, with each sample in duplicate. After washing six times with PBST, the plates were incubated with $50 \mu \mathrm{l} \mathrm{HRP-conjugated} \mathrm{goat} \mathrm{anti} \mathrm{pig} \mathrm{IgG}$ for $30 \mathrm{~min}$ at $37^{\circ} \mathrm{C}$. Then, the plates were washed again and finally incubated with 3,3',5,5'-tetramethylbenzidine (TMB, Sigma) for color development. After $10 \mathrm{~min}$ of incubation at room temperature, the enzymatic reaction was stopped with $2 \mathrm{M} \mathrm{H}_{2} \mathrm{SO}_{4}$ and the horseradish peroxidase product was quantified at $\mathrm{A} 450\left(\mathrm{OD}_{450}\right)$ with an automatic plate reader (Bio-Tek Instruments, Inc., Winooski, VT, USA). All data were measured in triplicate, and the mean value of $\mathrm{OD}_{450}$ values and standard deviation for each sample were calculated.

\section{Optimization of ELISA working conditions}

According to the procedure described above, the optimal antigen coating concentration and serum dilution were determined by checkerboard titration (Crowther 2000). Briefly, GP5 protein was immobilized onto 96-well microtiter plates in serial twofold dilutions from $5.00 \mu \mathrm{g} / \mathrm{mL}$ to $0.15 \mu \mathrm{g} / \mathrm{mL}$. Correspondingly, PRRSV positive and negative swine sera were also diluted in serial twofold dilutions from 1:100 to 1:3200 for optimization. Following determination of the optimal antigen concentration and antiserum dilution, the optimal conjugate dilution was also defined. The HRP-conjugated goat anti pig IgG were added onto the plates at dilutions of 1:500, 1:1000, 1:2000, 1:4000, 1:8000 and 1:16000. The conditions giving the highest OD450 ratio between positive and negative serum $(\mathrm{P} / \mathrm{N}$ value $)$ with the $\mathrm{OD}_{450}$ value of the positive serum close to 1.0 were scored as the optimal working conditions in ELISA.

After the conditions mentioned above were fixed, the coating buffer in ELISA was optimized from 0.1 $\mathrm{M} \mathrm{NaOH}$ solution at $\mathrm{pH} 13(\mathrm{NaOH}), 0.1 \mathrm{M}$ HCL solution at $\mathrm{pH} 3.0$ (HCL), $0.05 \mathrm{M}$ Tris-HCL buffer at pH 8.5 (TBS), double distilled water at $\mathrm{pH} 6.7$ (DDW), 0.05 M phosphate-buffered saline at $\mathrm{pH} 7.4$ (PBS) to $0.05 \mathrm{M}$ carbonate-bicarbonate buffer at $\mathrm{pH}$ 9.6 (CBS). Subsequently, to determine the optimal reaction time for serum samples and the conjugate, the reaction was stopped by washing with PBST after incubating for $10 \mathrm{~min}, 20 \mathrm{~min}, 30 \mathrm{~min}, 45 \mathrm{~min}, 60 \mathrm{~min}$ and $90 \mathrm{~min}$, respectively.

\section{Validation of GP5-ELISA}

To determine the cut-off value for this assay, 50 PRRSV-negative sera were tested by GP5-ELISA, and the cut-off value was determined as the mean $\mathrm{OD}_{450}$ of the negative sera $(\mathrm{X})$ plus three times of the standard deviation $(\mathrm{X}+3 \mathrm{SD})$. GP5-ELISA was then validated with IDEXX ELISA using 566 field serum samples. The IDEXX PRRS Herchek ELISA (IDEXX Laboratories, USA) was performed according to the manufacturer's instructions with a $\mathrm{S} / \mathrm{P}$ cut-off value of 0.4 . The diagnostic sensitivity (DSN), diagnostic specificity (DSP), and accuracy of GP5-ELISA were calculated according to the formula: $\mathrm{DSN}=\mathrm{TP} /(\mathrm{TP}+\mathrm{FN}) \backslash 100 ; \mathrm{DSP}=\mathrm{TN} /(\mathrm{TN}$ $+\mathrm{FP}) \backslash 100$, and Accuracy $=(\mathrm{TP}+\mathrm{TN}) /$ total number of serum samples tested $\times 100$, where $\mathrm{TP}, \mathrm{FN}, \mathrm{TN}$, and FP indicated true-positive, false-positive, true-negative and false-negative, respectively. To detect the specificity of the GP5-ELISA, positive sera against PCV2, CSFV, JEV, PRV and PPV were tested according to the GP5-ELISA procedure. 


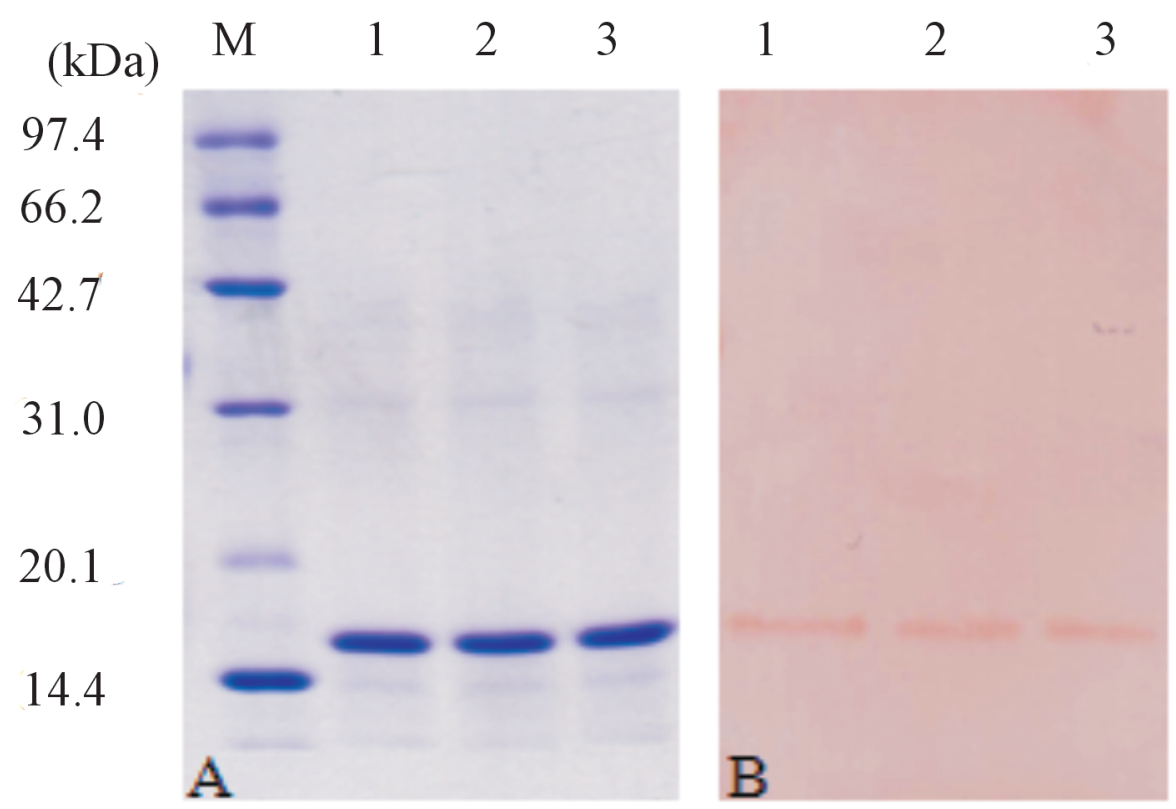

Fig. 1. Identification of purified GP5 by SDS-PAGE (A) and Western blot (B). (A) Lane M, Mid-range protein molecular weight marker (kDa); lanes 1-3, purified GP5 in collected tubes 1-3. (B) Purified GP5 reacted specifically with anti-PRRSV swine polyclonal antibodies.

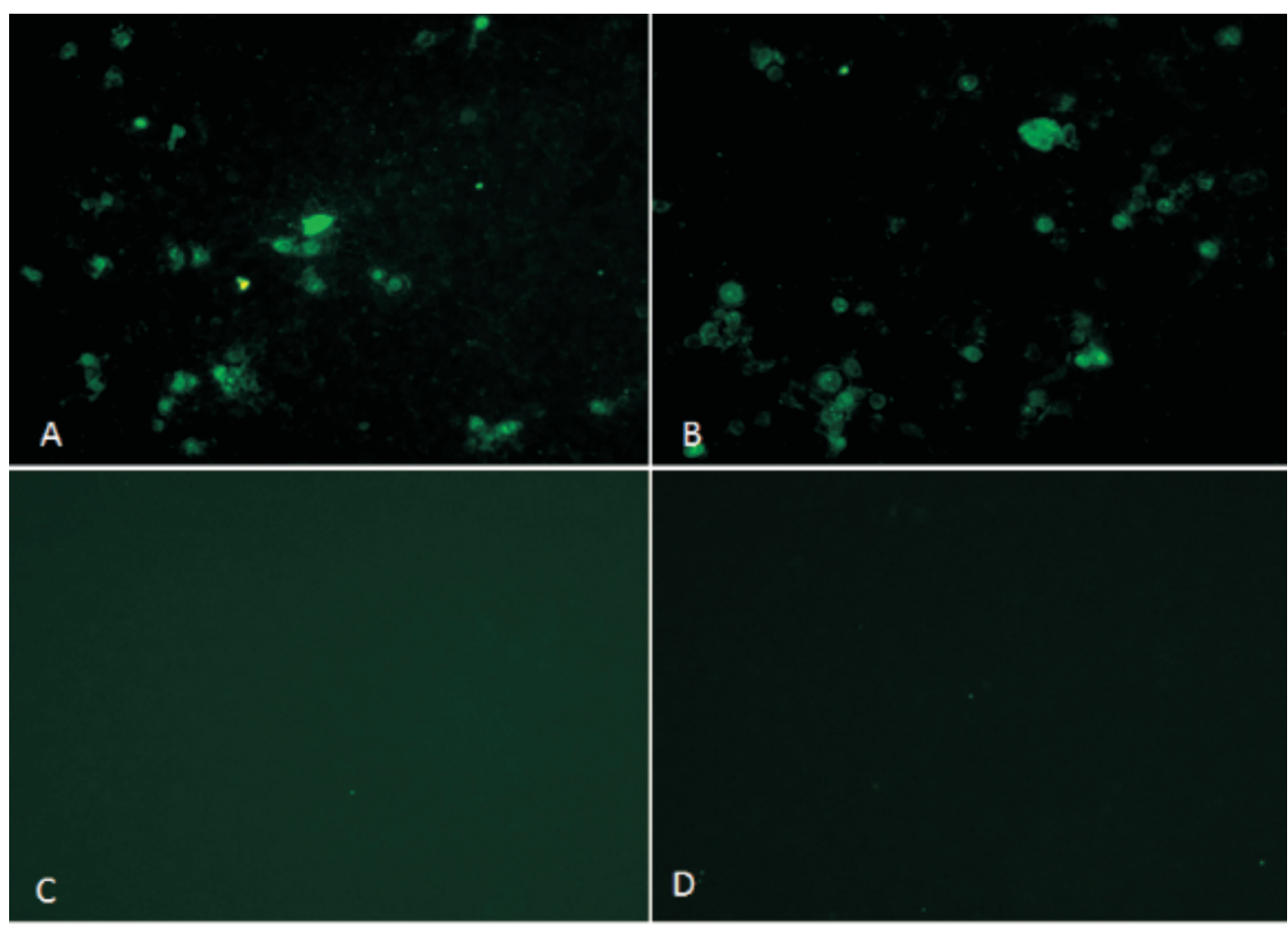

Fig. 2. Immunofluorescence assay (IFA). (A) reaction between PRRSV-positive swine serum and PRRSV-infected MARC-145 cells; (B) reaction between GP5-immunized mouse polyclonal serum and PRRSV-infected MARC-145 cells; (C) reaction between PRRSV-positive swine serum and mock-infected MARC-145 cells; (D) reaction between GP5-immunized mouse polyclonal serum and mock-infected MARC-145 cells. 


\section{Results}

\section{Immunogenicity of GP5 protein}

GP5 protein with the expected molecular weight of $16.6 \mathrm{kDa}$ was expressed as inclusion body and purified by Ni-chelating affinity chromatography. Denatured GP5 was refolded by gradual dialysis against decreasing concentrations of urea. The refolding yield was approximately $50 \%$ confirmed with the BCA Protein Assay Kit. The overall yield of immunogenic GP5 protein was over $45 \mathrm{mg} / \mathrm{L}$ cell culture. SDS-PAGE showed the purity of GP5 protein was up to $90 \%$, and western blot revealed that the expressed GP5 could react with swine sera against PRRSV (Fig. 1). IFA showed mouse polyclonal antibodies against GP5 protein bound specifically with PRRSV-infected MARC-145 cells (Fig. 2).

\section{Optimization of GP5 ELISA procedure}

In checkerboard ELISAs, the optimal antigen concentration and serum sample dilution were determined at $2.5 \mu \mathrm{g} / \mathrm{mL}$ and 1:800 (Fig. 3a and 3b). The optimal dilution of the conjugate was set at 1:4000 (Fig. 3c). After determination of the above-mentioned conditions, it was found that $0.05 \mathrm{M} \mathrm{CBS}$ at $\mathrm{pH} 9.6$ was the best coating buffer (Fig. 3d).

\section{Validation of GP5 ELISA}

The cut-off value of GP5-ELISA was determined as 0.35 after test 50 PRRSV-negative serum samples. Samples with OD450 value equal to or greater than 0.35 were regarded as positive. Samples were considered as negative with OD450 value less than 0.35. Compared with IDEXX-ELISA, the DSN, DSP, and accuracy of GP5-ELISA were $81.39 \%, 75.96 \%$, and $80.39 \%$, respectively (Table 1). No cross-reactions of GP5-ELISA were found with positive sera against other important swine pathogens including PCV2, CSFV, JEV, PRV and PPV (Table 2).

Table 1. Comparison of GP5 ELISA with IDEXX ELISA using 566 field serum samples.

\begin{tabular}{cccc}
\hline \multirow{2}{*}{ GP5-ELISA } & \multicolumn{3}{c}{ IDEXX } \\
\cline { 2 - 4 } & positive & negative & total \\
\hline Positve & 376 & 25 & 401 \\
Negative & 86 & 79 & 165 \\
Total & 462 & 104 & 566 \\
\hline
\end{tabular}

Table 2. Specificity of GP5-ELISA. The $\mathrm{OD}^{450}$ values from the reaction between GP5 and other positive sera against important swine pathogens were less than 0.35 , indicating there was no cross-reaction.

\begin{tabular}{cc}
\hline Antisera & OD $_{450}$ Value $($ Mean \pm SD) \\
\hline PCV2 & $0.097 \pm 0.029$ \\
CSFV & $0.121 \pm 0.085$ \\
JEV & $0.204 \pm 0.012$ \\
PRV & $0.227 \pm 0.009$ \\
PPV & $0.220 \pm 0.009$ \\
PRRSV(+) & $2.166 \pm 0.141$ \\
PRRSV(-) & $0.176 \pm 0.006$ \\
\hline
\end{tabular}

\section{Discussion}

Nowadays, PRRSV infection continues to be a great threat to the swine industry, causing huge economic losses worldwide each year. Vaccination is the main strategy to control PRRS. Current PRRS vaccines include live attenuated, inactivated, and subunit vaccines. These vaccines provide protection primarily through humoral immunity. GP5 is the primary structural protein of PRRSV and a promising vaccine candidate. GP5-binding Abs of pigs seem to be the primary PRRSV neutralizing Abs, since the well-timed appearance in sera of all VR-2332-infected pigs of GP5 peptide binding Abs correlated 100\% with the appearance of neutralizing Abs (Plagemann et al. 2002). Additionally, among the proteins (M, GP2a, GP3, GP4 and GP5) that have been reported to be capable of inducing neutralizing antibodies, GP5 seems to induce neutralizing antibodies that appear to be the most relevant for protection (Kimman et al. 2009). Thus, GP5 protein can be used as a diagnostic antigen for screening PRRSV infections and evaluating vaccine efficacy.

GP5 is a typical type I glycoprotein and is composed of 200 amino acids, containing a signal peptide (residues 1-31), an ectodomain, three trans-membrane regions (residues 64-82, 87-99, and 107-129) and an endodomain. For the large scale production of foreign proteins, the Esherichia coli expression system is optimal, although many other expression systems exist, including mammalian cells, transgenic plants, and the yeasts. Previously we demonstrated that full-length GP5 protein could not be expressed in $E$. coli Rosetta(DE3), which might be caused by the strong hydrophobicity of the trans-membranes regions. In this study, a GP5 protein containing the extra- and intra-cellular domain was used as the diagnostic antigen in the development of an indirect ELISA to help swine practitioners monitor and control PRRSV infections. GP5 protein was successfully overexpressed as inclusion bodies in E. coli and 

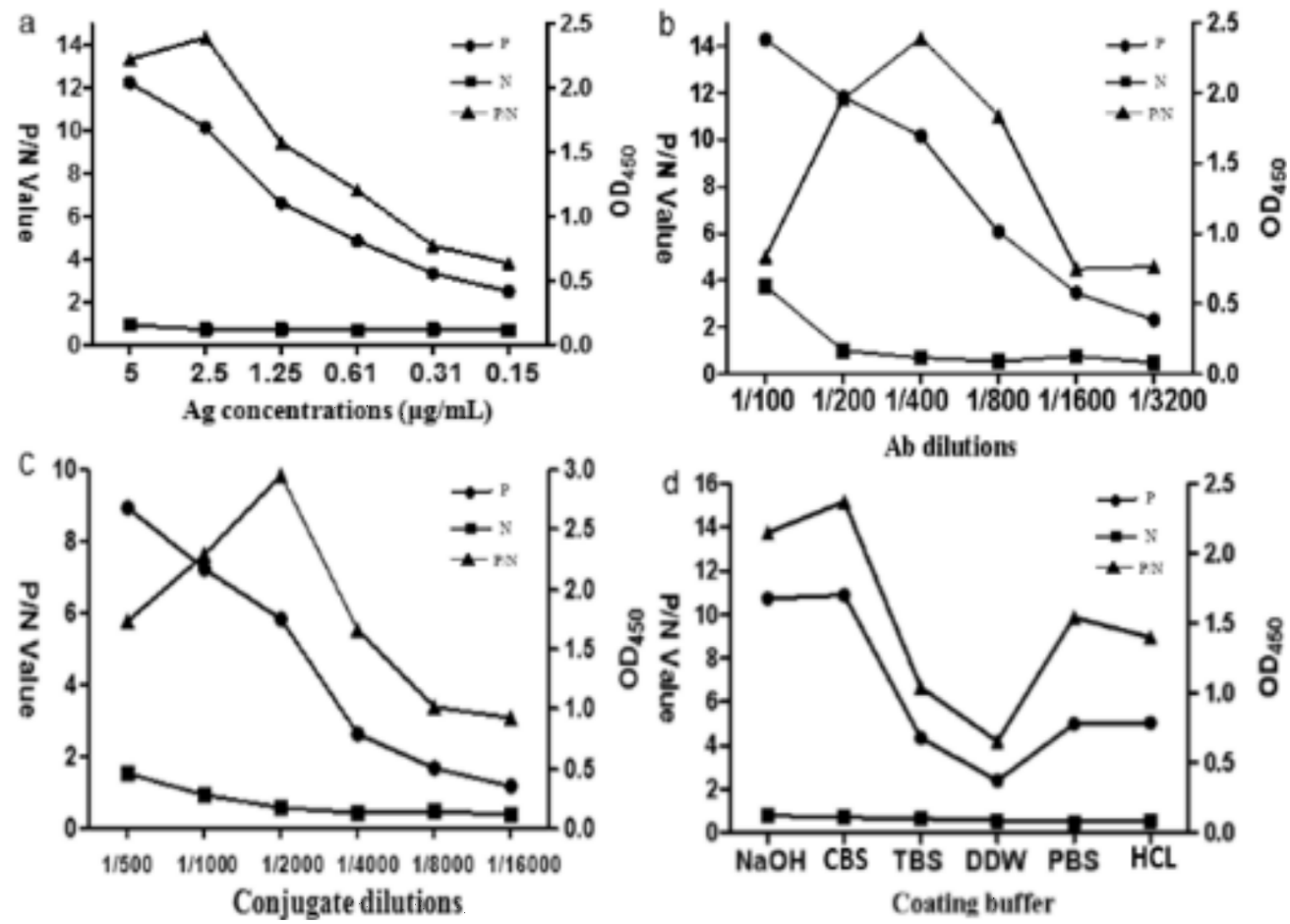

Fig. 3. Optimization of ELISA working conditions. The optimal antigen concentrations (a) and serum sample dilutions (b), dilutions of the conjugate (c), and the coating buffers (d) were determined through checkerboard titration.

purified under denatured conditions by Ni-chelating affinity chromatography. The active GP5 was recovered efficiently from inclusion bodies with a refolding yield of approximate $50 \%$, and the overall yield of GP5 in E. coli flask culture was more than 45 $\mathrm{mg} / \mathrm{L}$. Western blot and IFA showed that GP5 protein possessed high immunogenicity by reacting specifically with PRRSV-positive serum. These results indicated that large amount of highly immunogenic GP5 protein was obtained, which facilitaed the development of the GP5 protein-based ELISA. After optimization of the main reagents and the determination of a cut-off value, 566 clinical sera were tested by GP5-ELISA and IDEXX ELISA, the DSN, DSP, and accuracy of GP5-ELISA were $81.39 \%, 75.96 \%$, and $80.39 \%$, respectively. Besides, GP5-ELISA is highly specific, showing no cross-reactions with sera against other important swine pathogens. Hence, GP5 is a good diagnostic antigen and the GP5 protein-based ELISA has the potential to be used in the field.

\section{Acknowledgements}

This work was supported by grants from China Agriculture Research System (No. CARS-36), the Pig Industry Technology System Innovation Team Project of Henan Province (S2012-06), and the Natural Science Fund for phDs in Xinxiang Medical University (XYBSKYZZ201519).

\section{References}

Albina E, Leforban Y, Baron T, Plana Duran JP, Vannier $P$ (1993) An enzyme linked immunosorbent assay (ELISA) for the detection of antibodies to the porcine reproductive and respiratory syndrome (PRRS) virus. Ann Rech Vet 23: 167-176.

Cho HJ, Deregt D, Joo HS (1996) An ELISA for porcine reproductive and respiratory syndrome: production of antigen of high quality. Can J Vet Res 60: 89-93.

Collins JE, Benfield DA, Christianson WT, Harris L, Hennings JC, Shaw DP, Goyal SM, McCullough S, Morrison RB, Joo HS, Gorcyca D, Chladek D (1992) Isolation of swine infertility and respiratory syndrome virus (isolate ATCC VR-2332) in North America and experimental reproduction of the disease in gnotobiotic pigs. J Vet Diagn Invest 4: 117-126.

Crowther JR (2000) The ELISA Guidebook. In: Methods Mol Biol. The Humana Press, USA, pp 1-448.

Dea S, Wilson L, Therrien D, Cornaglia E (2000) Competitive ELISA for the detection of antibodies to porcine reproductive and respiratory syndrome virus using recombinant E. coli-expressed nucleocapsid protein as antigen. J Virol Methods 87: 109-122.

Ferrin NH, Fang Y, Johnson CR, Murtaugh MP, Polson DD, Torremorell M, Gramer ML, Nelson EA (2004) Validation of a blocking enzyme-linked immunosorbent assay for detection of antibodies against porcine reproductive and respiratory syndrome virus. Clin Diagn Lab Immunol 11: 503-514.

Foti M, Bottari T, Daidone A, Rinaldo D, De Leo F, Foti S, Giacopello C (2008) Serological survey on Aujeszky's disease, swine influenza and porcine reproductive and respiratory syndrome virus infections in Italian pigs. Pol J Vet Sci 11: 323-325. 
Gao ZQ, Guo X, Yang HC (2004) Genomic characterization of two Chinese isolates of porcine respiratory and reproductive syndrome virus. Arch Virol 149: 1341-1351.

Gonin P, Pirzadeh B, Gagnon CA, Dea S (1999) Seroneutralization of Porcine Reproductive and Respiratory Syndrome Virus Correlates with Antibody Response to the GP5 Major Envelope Glycoprotein. J Vet Diagn Invest 11: 20-26.

Keffaber KK (1989) Reproductive failure of unknown etiology. Am Assoc Swine Pract Newsletter 1: 1-10.

Kimman TG, Cornelissen LA, Moormann RJ, Rebel JM, Stockhofe-Zurwieden N (2009) Challenges for porcine reproductive and respiratory syndrome virus (PRRSV) vaccinology. Vaccine 27: 3704-3718.

Meulenberg JJ, Hulst MM, de Meijer EJ, Moonen PL, den Besten A, de Kluyver EP, Wensvoort G, Moormann RJ (1993) Lelystad virus, the causative agent of porcine epidemic abortion and respiratory syndrome (PEARS), is related to LDV and EAV. Virology 192: 62-72.

Nelson EA, Christopher-Hennings J, Benfield DA (1994) Serum immune responses to the proteins of porcine reproductive and respiratory syndrome (PRRS) virus. J Vet Diagn Invest 6: 410-415.

Nowicka D, Czopowicz M, Mickiewicz M, Szaluś-Jordanow O, Witkowski L, Bagnicka E, Kaba J (2014) Diagnostic performance of ID screen MVV-CAEV Indirect Screening ELISA in identifying small ruminant lentiviruses-infected goats. Pol J Vet Sci 17: 501-506.

Pejsak Z, Truszczyński M, Niemczuk K, Kozak E, Markowska-Daniel I (2014) Epidemiology of African Swine Fever in Poland since the detection of the first case. Pol J Vet Sci 17: 665-672.

Plagemann PG, Rowland RR, Faaberg KS (2002) The primary neutralization epitope of porcine respiratory and reproductive syndrome virus strain VR-2332 is located in the middle of the GP5 ectodomain. Arch Virol 147: 2327-2347.
Plagemann PG (2006) Peptide ELISA for measuring antibodies to $\mathrm{N}$-protein of porcine reproductive and respiratory syndrome virus. J Virol Methods 134: 99-118.

Pirzadeh B, Dea S (1997) Monoclonal antibodies to the ORF5 product of porcine reproductive and respiratory syndrome virus define linear neutralizing determinants. J Gen Virol 78: 1867-1873.

Ren X, Wang M, Yin J, Ren Y, Li G (2010) Heterologous expression of fused genes encoding the glycoprotein 5 from PRRSV: a way for producing functional protein in prokaryotic microorganism. J Biotechnol 147: 130-135.

Wang Y, Xing G, Guo J, Qiao S, Lu Q, Li Q, Zhang $\mathrm{G}$ (2011) Immunogenicity of the glycoprotein 5 truncated trans-membrane regions of porcine reproductive and respiratory syndrome virus. Afr $\mathrm{J}$ Biotech 10: $18266-18273$.

Wensvoort G, Terpstra C, Pol JM, ter Laak EA, Bloemraad M, de Kluyver EP, Kragten C, van Buiten L, den Besten A, Wagenaar F, Broekhuijsen JM, Moonen PL, Zetstra $\mathrm{T}$, de Boer EA, Tibben HJ, de Jong MF, van 't Veld $\mathrm{P}$, Greenland GJ, van Gennep JA, Voets MT, Verheijden JH, Braamskamp J (1991) Mystery swine disease in the Netherlands: the isolation of Lelystad virus. Vet $Q$ 13: $121-130$.

Wernicki A, Urban-Chmiel R, Stęgierska D, Adaszek Ł, Kalinowski M, Puchalski A, Dec M (2015) Detection of the bovine viral diarrhoea virus (BVDV) in young beef cattle in eastern and south-eastern regions of Poland. Pol J Vet Sci 18: 141-146.

Yoon IJ, Joo HS, Christianson WT, Kim HS, Collins JE, Morrison RB, Dial GD (1992) An indirect fluorescent antibody test for the detection of antibody to swine infertility and respiratory syndrome virus in swine sera. $\mathrm{J}$ Vet Diagn Invest 4: 144-147. 